\title{
Health-Related Quality of Life Among People
} Living with Human Immunodeficiency Virus on Highly Active Antiretroviral Therapy in Ethiopia: PROQOL-HIV Based Survey

This article was published in the following Dove Press journal:

Patient Related Outcome Measures

\section{Tsegaye Melaku (D) \\ Girma Mamo \\ Legese Chelkeba (D) \\ Tesfahun Chanie}

Department of Clinical Pharmacy, School of Pharmacy, Institute of Health, Jimma University, Jimma, Ethiopia
Correspondence: Tsegaye Melaku Tel +25I 913765609

Email tsegaye.melaku@ju.edu.et
Background: As infection with the Human Immunodeficiency Virus (HIV) has evolved into a chronic disease, perceived health-related quality of life (HRQoL) is becoming a prominent and important patient-reported outcome measure in HIV care. This study aimed to assess HRQoL among people living with HIV on highly active antiretroviral therapy and factors associated with HRQoL in Ethiopia.

Methods: An institution-based cross-sectional study was conducted among 160 HIV-infected patients who were initiated highly active antiretroviral therapy at Jimma University Medical Center in 2016. HRQoL was assessed using the patient-reported outcome quality of life-HIV (PROQOL-HIV) measuring scale. Linear regressions were used to identify factors associated with outcome. Statistical significance was considered at p-value $<0.05$.

Results: Out of a total of 160 participants, $63.13 \%$ were females. The mean $( \pm S D)$ age of study participants was $41.47 \pm 9.45$ years. The median baseline $\mathrm{CD}_{4}+$ cell count was 182.00 cells/ $\mu \mathrm{L}$ (IQR: $104.53-262.40$ cells $/ \mu \mathrm{L})$. The mean $( \pm \mathrm{SD})$ score of PROQOL-HIV scale domains was $77.58 \pm 15.11,58.32 \pm 7.79,61.75 \pm 17.95,85.07 \pm 15.67,76.92 \pm 20.52,80.00$ $\pm 16.83,74.37 \pm 1.47,81.45 \pm 8.17$ for physical health and symptoms, emotional distress, health concerns, body change, intimate relationships, social relationships, stigma, and treatment impact domains, respectively. Second line antiretroviral therapy showed a negative effect on the quality of life, especially on the treatment impact domain $(\beta=-6.301)$. Cotrimoxazole preventive therapy had a significant positive effect on the physical health and symptoms of HIV patients $(\beta=+8.381, \mathrm{p}<0.05)$. Advanced disease $(\beta=-2.709, \mathrm{p}<0.05)$, and non-communicable disease comorbidity $(\beta=-14.340, \mathrm{p}<0.001)$ showed a significant negative effect on physical health and symptoms.

Conclusion: Several behavioral, clinical \& immunological factors were negatively associated with health-related quality of life. The double burden of chronic non-communicable disease(s) and the impact of treatment were highly significant in all dimensions of HRQoL measures. Therefore, with HRQoL emerging as a key issue for HIV-infected patients, its routine assessment and appropriate interventions at each clinic visit would be very crucial. Keywords: human immunodeficiency virus, health-related quality of life, patient-reported outcome

\section{Introduction}

The coming of anti-retroviral therapy (ART) and its widespread availability in many settings has reduced the mortality rate among people living with human 
immunodeficiency virus (PLHIV). ${ }^{1}$ As the longevity of PLHIV improves as a result of ART, improvement of healthrelated quality of life (HRQoL) these patients has become an important issue for clinicians, researchers, and policymakers. ${ }^{2}$ According to the world health organization (WHO), quality of life is defined as an individuals' perception of their position in life in the context of the culture and value systems in which they live and concerning their goals, expectations, standards, and concerns. ${ }^{3}$ This definition considers individuals' satisfaction on their physical, psychological, social relationships, environment, and spiritual aspects of their life. ${ }^{3}$ Though the physical well-being is improved with ART, it does not guarantee mental and social well-being among PLHIV. ${ }^{4}$

Routine intake of antiretroviral drugs is mandatory to achieve or to maintain virologic and immunologic outcomes. ${ }^{5}$ However, these are not the only outcomes that should be taken into consideration. In any chronic disease (both infectious and non-infectious), assessing HRQoL has become an essential outcome of therapy. HRQoL assessments provide valuable feedback about care-related interventions and they are very important in treatment outcomes analyses. HRQoL is vital to clinical practice because it is used to track changes in functional status over time for chronic illness, evaluate and monitor treatment effects, improve patient-provider communication, and adherence to medications. ${ }^{6}$ HRQoL among human immunodeficiency virus/acquired immune deficiency syndrome (HIV/AIDS) can be affected by several factors which may be categorized into individual, service delivery, community, and socialdemographic factors. Some of the factors are intertwined, for instance, educational attainment may be linked to selfcare. Through education, an individual can be equipped with self-care skills. Marital status is linked to social support because in most cases, married persons have families that can be a source of social support. Service delivery factors, like type and duration of ART regimen and concomitant medications for other illnesses, should be considered. ${ }^{7}$

Various HRQoL assessment tools have been used in PLHIV, most commonly as part of research trials. These tools can be classified as either generic or disease-specific, with the former designed to be used in a variety of populations to provide a general overview of HRQoL and the latter designed to measure health status in specific groups (diseases). A long ago, many HRQoL measures used in HIV research were developed before the HAART era, including the Medical Outcomes Survey HIV Health Survey (MOS-HIV), Functional Assessment of HIV Infection (FAHI), HIV Overview of Problems-Evaluation
System (HOPES), HIV/AIDS Targeted QOL (HAT-QOL), AIDS Health Assessment Questionnaire (AIDS-HAQ), Multidimensional QOL Questionnaire for HIV/AIDS (MQoL-HIV). However, these measures may not fully address the impact of contemporary treatments and not sensitive\& specific to detect HRQoL changes. Unfortunately, much as a measurement of HRQoL data is important, patients perceive the effects of ART on their quality of life as a trade-off between poorer quality of life and being alive. ${ }^{8}$

Therefore, currently, to measure the impact of contemporary treatments, sensitive measure for HRQoL was developed $\&$ used in some of the pieces of literature and called as patient-reported outcomes quality of life HIV instrument (PROQOL-HIV). We used this HRQoL measuring scale for our current study to assess the association of contemporary HAART regimens with health-related quality of life. HRQoL information from this study will inform healthcare practitioners not only about the physical but also the mental wellbeing of their patients and overall functionality. This will increase their suspicion index of detecting illness, thus enhancing the quality of service provided to their patients. By and large, our study aimed to assess health-related quality of life and factors associated with HRQoL among HAART initiated HIV infected patients on follow up at Jimma University Medical Center, Ethiopia.

\section{Methods}

\section{Study Design and Settings}

This is a cross-sectional study done among HIV infected patients who initiated on HAART at the ART clinic of Jimma University Medical Center (JUMC) from April to August 2016. Patients were eligible for the present study if they were on HAART at least for 6 months, aged 18 years, and if they gave their informed consent to participate in the study. Currently, a total of 7288 HIV-infected individuals were registered and attending JUMC comprehensive chronic care and training center. Out of these, 4,277 $(58.6 \%)$ were on HAART, and the remaining 3011 $(41.4 \%)$ were HAART naive. The center works 7 days a week in an outpatient setting and provides holistic HIV care by employing clinicians, counselors and social workers.

\section{Sample Size and Sampling Techniques}

A total of 160 adult patients who fulfill the inclusion criteria and accepted to participate were included in the study. The sampling of the study population was done 
based on a systematic random sampling technique. There was no difference between those participating and those who did not. But we included only adult patients who initiated on HAART, as the PROQOL-HIV scale included the impact of the treatment.

\section{Data Collection Tools and Outcome Measure}

In this study, the principal investigators and research assistants used English versions validated PROQOL-HIV tool. ${ }^{9}$ The tool was also translated to other two local languages (i.e. Afaan Oromoo and Amharic), which was also backtranslated to English for consistency by health care professionals native to the languages. The version of the tool was determined by the language for which the participant felt comfortable to be interviewed. This tool was administered via face to face interview. The dimensions were measured on a Likert scale and mainly quantitative data was collected. Other information such as socio-demographic, behavioral\& clinical data was included in the questionnaire to meet the objectives of the study other than the HRQoL items. The PROQOL-HIV scale is used to summarize a patient's HRQoL as eight-scale scores within the past two weeks. PROQOL-HIV questionnaire administration and scoring are fast, which comprises 38 items, 1 reverse-scored item, and 4 summated subscales.

These eight sub-scales (factors) is categorized into the following domains: physical health and symptoms (PHSs, 9 items), treatment impact (TI, 10 items), emotional distress (ED, 4 items), health concerns (HCs, 4 items), body change (BC, 4 items), intimate relationships (IR, 3 items), social relationships (SR, 2 items), and stigma (ST, 2 items). However, a single item assessing general health during the past 2 weeks and four further items dealing with religious beliefs, finance, parenthood, and satisfaction with care are used to gather additional information related to patient's HRQoL and are not part of the scoring scheme in this study.

The sub-scales were derived from summed Likert item values (range 0-4 points) expressed as a final score on a $0-100$ scale with higher values indicating better HRQoL. The mean \pm SD scores for each of the domains were calculated for each domain.

Participants rated the extent to which they had experienced each of the 38 items over the past 2 weeks on a 5 -point scale ranging from $1=$ never to $5=$ always. One item was an exception, where response categories ranged from $1=$ very good to $5=$ very poor. The scoring was done based on the number of items included in each domain (see the formula below). The main properties, including the validity and reliability of the questionnaire and comparisons with other commonly used HRQoL instruments, have previously been described elsewhere. ${ }^{9}$

$$
\begin{aligned}
& \text { Intimate Relationships(IR) domain } \\
& \qquad=100-(I R 1+I R 2+I R 3) \times 100
\end{aligned}
$$

IR: has three questions (items) to be asked \& the maximum score is $3 \times 4=12$

Cronbach's alpha was calculated to determine the internal consistency of the PROQOL-HIV tool. All domains of the PROQOL-HIV had a high value of Cronbach's alpha $(\alpha>0.7)$. The Cronbach's alpha coefficient of physical health and symptoms (0.74), emotional distress (0.72), health concerns $(0.70)$, body change $(0.72)$, social relationships (0.79), intimate relationships (0.71), stigma (0.81), and treatment impact (0.78) were adequate, indicating acceptable reliability of the questionnaire.

\section{Data Collection Procedure}

Two trained data collectors (nurses) interviewed the study participants and reviewed patient charts and medical records for the respective information after all data collection tools were pre-tested. Data about HRQoL were interviewed by using a standard questionnaire mentioned above (PROQOL-HIV). Patient self-reports and using medication (s) as a proxy indicator for chronic non -communicable disease diagnosis was used to identify the presence of non-communicable diseases (NCDs). Since the study was conducted in a clinic setting and individual factors like CD4+ cell counts, co-morbidities, self-reported symptoms, and immunological state were considered.

\section{Data Processing \& Analysis}

We calculated descriptive statistics for patient characteristics. Demographic data were reported as frequencies and percentage or mean (SD) values. Only patients with complete data on all explanatory variables were considered in the final model and included in the analyses. Participant characteristics and HRQoL outcomes were tabulated and stratified. Proportions were compared for categorical variables. Continuous variables were presented as medians and inter-quartile ranges unless otherwise stated. The main study outcome was HRQoL as measured by PROQOLHIV, which were also reported as mean (SD) values. Linear regression was used to identify the associations between PROQOL-HIV scale domains and demographic, 
behavioral, clinical and immunological characteristics of the patients. Results were presented as B-coefficient, standard error, and p-value. Statistical analysis was performed using IBM SPSS software, version 20.0 (IBM Corp., Armonk, NY). Statistical significance was set at $\mathrm{p}<0.05$.

\section{Ethical Considerations}

Ethical clearance \& approval was obtained from the institutional review board (IRB) of Jimma University. The data that were collected from the JUMC ART clinic was preceded by a formal request letter from Jimma University. Written informed consent was taken from each study participant after a clear orientation of the study objective. The raw data were not made available to anyone and not used as the determinant of the participant. All steps in data collection and compilation were conducted and supervised by the principal investigators. Strict confidentiality was assured through anonymous recording and coding of questionnaires and placed in a safe place. The patient got full right not to participate and as well as leave the study at any time during the study time.

\section{Results}

\section{Characteristics of the Study Participants}

In this study, all the variables were assessed crosssectionally during the patient's interview. Out of a total of 160 participants, $63.13 \%$ were females. The mean (SD) age of study participants was 41.479 .45 years. About half of them were in the age range of 35-50 years. About 55\% of study participants were married and about $76.25 \%$ were living with immediate family. Most of them attended formal education and only $11.25 \%$ could not read and write. Behavioral measurements of study participants showed that about $52.5 \%, 18.13 \%$, and $16.25 \%$ were alcohol consumers, chat chewer and smoker respectively (Table 1).

Concerning clinical and immunological characteristics of study participants, approximately two-thirds and $35.62 \%$ of patients were on cotrimoxazole (CTX) and Isoniazid (INH) preventive therapy, respectively. About two-thirds of patients had tuberculosis (TB) treatment history. The most common type of TB was pulmonary TB (45.37\%). The median baseline $\mathrm{CD}_{4}+$ cell count was 182.00 cells $/ \mu \mathrm{L}$ ) [Interquartile range (IQR): $104.53-262.4$ cells $/ \mu \mathrm{L}$ ]. At enrollment, more than half of patients had advanced diseases (WHO stage III-IV and $\mathrm{CD}_{4}+$ cell count less than 200 cells $/ \mu \mathrm{L}$ ). The median follows up duration was 74.75 months [IQR: 57.23-104.63 months] (Table 2).
Table I Socio-Demographic and Behavioral Characteristics of Study Participants

\begin{tabular}{|c|c|c|}
\hline \multicolumn{2}{|l|}{ Variables } & \multirow{2}{*}{$\begin{array}{l}\text { Number } \\
(\%)\end{array}$} \\
\hline Sex & $\begin{array}{l}\text { Male } \\
\text { Female }\end{array}$ & \\
\hline Age (years) & $\begin{array}{l}\text { Mean } \pm S D \\
18-35 \\
35-50 \\
\geq 50\end{array}$ & $\begin{array}{l}41.47 \pm 9.45 \\
56(35) \\
79(49.4) \\
25(15.6)\end{array}$ \\
\hline BMI $\left(\mathrm{kg} / \mathrm{m}^{2}\right)$ & $\begin{array}{l}<18 \\
18-24.9 \\
\geq 25\end{array}$ & $\begin{array}{l}22(13.75) \\
115(71.88) \\
23(14.37)\end{array}$ \\
\hline Marital status & $\begin{array}{l}\text { Single } \\
\text { Married } \\
\text { Divorced } \\
\text { Widowed }\end{array}$ & $\begin{array}{l}16(10) \\
88(55) \\
34(21.25) \\
22(13.75)\end{array}$ \\
\hline Educational status & $\begin{array}{l}\text { Could not read and write } \\
\text { Primary } \\
\text { Secondary } \\
\text { College and above }\end{array}$ & $\begin{array}{l}18(11.25) \\
92(57.50) \\
31(19.38) \\
19(11.87)\end{array}$ \\
\hline Residence & $\begin{array}{l}\text { Rural } \\
\text { Urban }\end{array}$ & $\begin{array}{l}31(19.38) \\
129(80.62)\end{array}$ \\
\hline $\begin{array}{l}\text { Monthly income } \\
\text { (USD) }\end{array}$ & $\begin{array}{l}\text { No regular income } \\
<40 \\
40-80 \\
80-120 \\
\geq 120\end{array}$ & $\begin{array}{l}78(48.75) \\
17(10.62) \\
31(19.38) \\
16(10) \\
18(11.25)\end{array}$ \\
\hline Living Status & $\begin{array}{l}\text { Living with immediate family } \\
\text { Living with extended family } \\
\text { Living alone }\end{array}$ & $\begin{array}{l}122(76.25) \\
28(17.50) \\
10(6.25)\end{array}$ \\
\hline Job/Occupation & $\begin{array}{l}\text { Gov't employee } \\
\text { Non-gov't employee } \\
\text { Self-employed } \\
\text { Unemployed }\end{array}$ & $\begin{array}{l}38(23.75) \\
14(8.75) \\
51(31.88) \\
57(34.37)\end{array}$ \\
\hline Behavioral Measures & $\begin{array}{l}\text { Current smoker } \\
\text { Current alcohol user } * * \\
\text { Chat chewer } \\
\text { Herbal/traditional medicine } \\
\text { use } ¥\end{array}$ & $\begin{array}{l}26(16.25) \\
84(52.50) \\
29(18.13) \\
40(25)\end{array}$ \\
\hline
\end{tabular}

Notes: ${ }^{¥}$ Those who use holy water as complementary medicine were included; IUSD=25 Ethiopian Birr. **Locally prepared alcohol such as "Tella" was included. Abbreviations: SD, Standard Deviation, BMI, Body Mass Index; USD, United States Dollar.

\section{Health-Related Quality of Life (HRQoL)}

Concerning HRQoL, the overall mean SD score of PROQOL-HIV domains is $77.58 \pm 15.11,58.32 \pm 7.79$, $61.75 \pm 17.95, \quad 85.07 \pm 15.67, \quad 76.92 \pm 20.52, \quad 80.00$ 
Table 2 Clinical and Immunological Characteristics of Study Participants

\begin{tabular}{|c|c|c|}
\hline \multicolumn{2}{|l|}{ Variables } & \multirow{2}{*}{$\begin{array}{l}\text { Number (\%) } \\
105(65.63) \\
55(34.37)\end{array}$} \\
\hline CTX prophylaxis & $\begin{array}{l}\text { Yes } \\
\text { No }\end{array}$ & \\
\hline INH prophylaxis & $\begin{array}{l}\text { Yes } \\
\text { No }\end{array}$ & $\begin{array}{l}57(35.62) \\
103(64.38)\end{array}$ \\
\hline TB treatment history & $\begin{array}{l}\text { Yes } \\
\text { No }\end{array}$ & $\begin{array}{l}108(67.50) \\
52(32.50)\end{array}$ \\
\hline Type of TB & $\begin{array}{l}\text { Pulmonary } \\
\text { Disseminated } \\
\text { Unknown }\end{array}$ & $\begin{array}{l}49(45.37) \\
29(26.85) \\
30(27.78)\end{array}$ \\
\hline Clinical stage (WHO) & $\begin{array}{l}\text { Stage I } \\
\text { Stage II } \\
\text { Stage III } \\
\text { Stage IV }\end{array}$ & $\begin{array}{l}13(8.12) \\
45(28.13) \\
72(45) \\
30(18.75)\end{array}$ \\
\hline Eligibility reason to HAART & $\begin{array}{l}\mathrm{CD}_{4}+\text { count } \\
\text { Clinical } \\
\mathrm{CD}_{4}+\text { count \& clinical }\end{array}$ & $\begin{array}{l}55(34.40) \\
19(11.90) \\
86(53.70)\end{array}$ \\
\hline Mean time on HAART (in months) & $49.13 \pm 17.09$ & \\
\hline $\begin{array}{l}\text { Median duration with HIV (in } \\
\text { months) }\end{array}$ & 74.75 (IQR: $57.23-104.63$ & \\
\hline Base line CD4+ count (cells $/ \mu \mathrm{L})$ & $\begin{array}{l}\text { Median (IQR) } \\
<200 \\
200-349 \\
350-499 \\
\geq 500\end{array}$ & $\begin{array}{l}182.00 \\
(104.53-262.4) \\
97(60.63) \\
49(30.62) \\
10(6.25) \\
4(2.5)\end{array}$ \\
\hline $\begin{array}{l}\text { Time elapsed from diagnosis to } \\
\text { HAART initiation (in months) }\end{array}$ & $\begin{array}{l}\text { Within the same month } \\
I-24 \\
\geq 24\end{array}$ & $\begin{array}{l}62(38.75) \\
64(40) \\
44(21.25)\end{array}$ \\
\hline Functional Status & $\begin{array}{l}\text { Working } \\
\text { Ambulatory }\end{array}$ & $\begin{array}{l}143(89.37) \\
17(10.63)\end{array}$ \\
\hline HAART Regimen & $\begin{array}{l}\text { Nevirapine based } \\
\text { Efavirenz based } \\
\text { Second line }\end{array}$ & $\begin{array}{l}59(36.88) \\
89(56.25) \\
11(6.87)\end{array}$ \\
\hline Prior regimen change & $\begin{array}{l}\text { Yes } \\
\text { No }\end{array}$ & $\begin{array}{l}100(62.5) \\
60(37.5)\end{array}$ \\
\hline NCD comorbidity & $\begin{array}{l}\text { Hypertension } \\
\text { Diabetes } \\
\text { Cardiac (Heart failure) } \\
\text { Asthma/COPD\# } \\
\text { Mental IIIness } \\
\text { Epilepsy } \\
\text { Multimorbidity** }\end{array}$ & $\begin{array}{l}22(13.75 \%) \\
19(11.88) \\
7(4.37) \\
6(3.75) \\
3(1.88) \\
3(1.88) \\
20(12.50)\end{array}$ \\
\hline
\end{tabular}

Notes: ${ }^{*}$ Only one COPD patient included; **co-occurrence 2 or more disease together. Abbreviations: CTX, Cotrimoxazole; INH, Isoniazid; TB, Tuberculosis; WHO, World Health Organization; CDC, Centers for Disease Control and Prevention; $\mathrm{SD}$, Standard Deviation; $\mathrm{CD}^{+}$, Cluster Differentiation, HAART, Highly Active Antiretroviral Therapy; COPD, chronic obstructive pulmonary disease; NCD, Noncommunicable disease. $\pm 16.83,74.37 \pm 1.47,81.45 \pm 8.17$ for [physical health and symptoms (PHS), emotional distress (ED), health concerns (HC), body change (BC), intimate relationships (IR), social relationships (SR), stigma (ST) and treatment impact (TI)] domains, respectively (Figure 1).

Assessment of patient-reported outcome quality of life with demographic and behavioral data showed that there was no statistically significant difference in mean score among male and female participants. Younger patients had a relatively lower mean score in all domains of the PROQOLHIV scale. All patients have a lower mean score on the emotional distress domain as compared to other domains. Patients with irregular income and positive for behavioral measures had a lower mean score of patient-reported outcome quality of life measures (Table 3 ).

The impact of clinical and immunological factors on patient-reported outcome quality of life revealed that those patients on preventive therapy (both Isoniazid and Cotrimoxazole) had a higher mean score on all domains of PROQOL-HIV scale, with the significant association on PHS, ED, HC domains $(\mathrm{p} \leq 0.05)$. Previous TB infection resulted in a lower mean score on the health concern $(\mathrm{p}=0.036)$ domain. Those patients who have advanced diseases (WHO clinical stage III \& IV) had a very low mean score on PHS ( $\mathrm{p}=0.006)$, ED $(\mathrm{p}=0.009)$ and $\mathrm{HC}(\mathrm{p}=0.018)$ domains. Non-communicable disease comorbidity resulted in a significantly lower mean score in all domains of patientreported outcome quality of life (Table 4).

Univariate regression analysis of potential factors associations with the 8 domains PROQOL-HIV scores were presented in Table 5, with co-variates grouped according to an indication of socio-demographic, behavioral, clinical \& immunological factors. Concerning factors associated with HRQoL, co-morbidity with $\mathrm{NCD}(\mathrm{s})$, duration with HIV and HAART, advanced disease, TB infection and being on the second line HAART regimen from clinical factors and smoking and alcohol use history from behavioral measures were negatively associated with HRQoL across all domains of PROQOL-HIV. Chronic NCD(s) were significantly associated with physical health and symptoms domain $(\beta=-14.340$; $p<0.001)$, health concern $(\beta=-4.014 ;(p<0.05)$, social $(\beta=$ $-4.213 ; \mathrm{p}<0.05)$ and intimate relationships $(\beta=-5.006$; $\mathrm{p}<0.05)$ ) domains and also being in WHO clinical stage III and IV at baseline were negatively related across all domains; significantly physical health of the patient $(\beta=-2.709 ; p<0.05)$.

Cotrimoxazole and isoniazid preventive therapy had a positive relationship with patient-reported outcome 


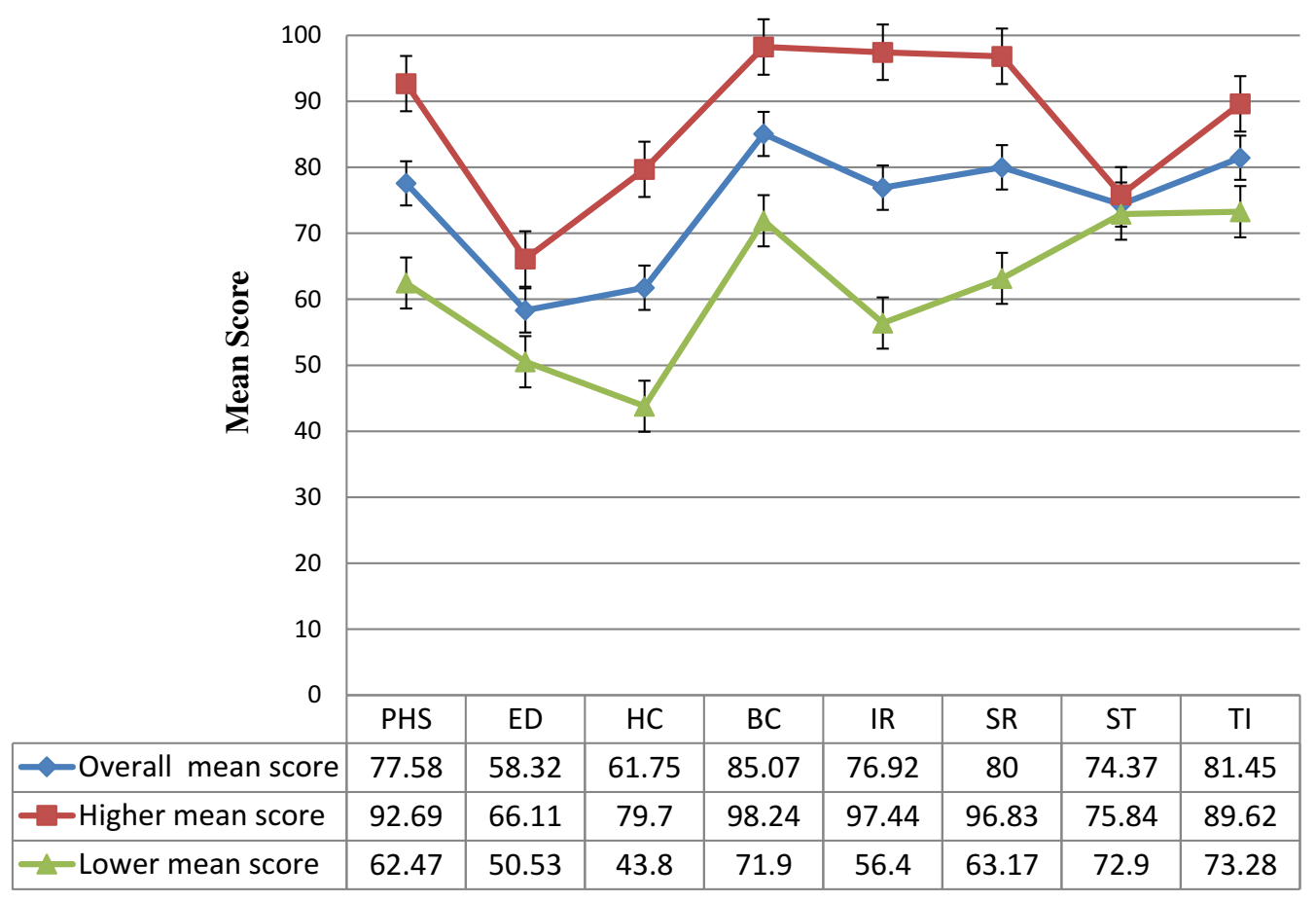

Figure I Mean $( \pm S D)$ Scores of 8 domains PROQOL-HIV of study participants [Error bars with standard errors].

Abbreviations: PHS, Physical health and symptoms; ED, emotional distress; HC, health concerns; BC, body change; IR, intimate relationships; SR, social relationships; ST, stigma; TI, treatment impact.

quality of life across the domains. Several sociodemographic factors and behavioral measures were more strongly associated with the physical health and symptoms domain than with the rest of the domains (Table 5).

\section{Discussion}

To our knowledge, in Ethiopia, a few facility-based studies have been conducted to assess the HRQoL among PLHIV and the impact of ART on them. ${ }^{10,11}$ Given the longevity achievable with current prophylactic and therapeutic strategies for persons with HIV infection, quality of life has emerged as a significant medical outcome measure and its enhancement as an important goal. ${ }^{11}$ Consequently, the impact of HIV infection on the dimensions of quality of life, including physical health and symptoms, treatment impact, emotional distress, health concerns, body change, intimate relationships, social relationships, and stigma, has emerged as a key issue for persons infected with HIV. Our current study, using the PROQOL-HIV instrument, assessed the HRQoL among PLHIV in JUMC and attempted to clarify the associated factors.

We assessed mean $( \pm \mathrm{SD})$ of HRQoL scores of our participants and performed a quantitative analysis concerning demographic, behavioral, clinical and immunological information. Accordingly, we found that there was no significant difference in the quality of life among male and female. However, there was a slight difference in the stigma domain $(\mathrm{p}=0.073)$ and emotional distress $(\mathrm{p}=0.091)$ component. Despite the lack of general agreement about gender differences in HRQoL, our current finding partially supported by other studies, on which women mostly reported lower HRQoL than men. ${ }^{12-14}$ This could be explained by the prevalence of mood disorders, anxiety disorders and psychosomatic disorders in females, which are suspected to affect this quality of life domains. ${ }^{15,16}$

Our study revealed that though statistically not significant, patients with older age scored lower mean score, all PROQOL-HIV scale domains, which is similar to other studies. ${ }^{17-21}$ This could be related to physical senescence among the elderly ${ }^{13-22}$ and also a positive relationship between younger age and better mental health. ${ }^{22}$ Similar to our study, different reports from different settings showed, even as if the diagnosis of HIV infection, in and of itself, can have deleterious ramifications, including the discontinuation of work, limitations in social activity, and dependence on others. Limited social support and poor coping skills also can negatively affect HRQoL. ${ }^{23,24}$ Socio-demographic factors, such as older age, female gender, unemployment, and low income, have been associated with poor HRQoL. ${ }^{24-27}$ 


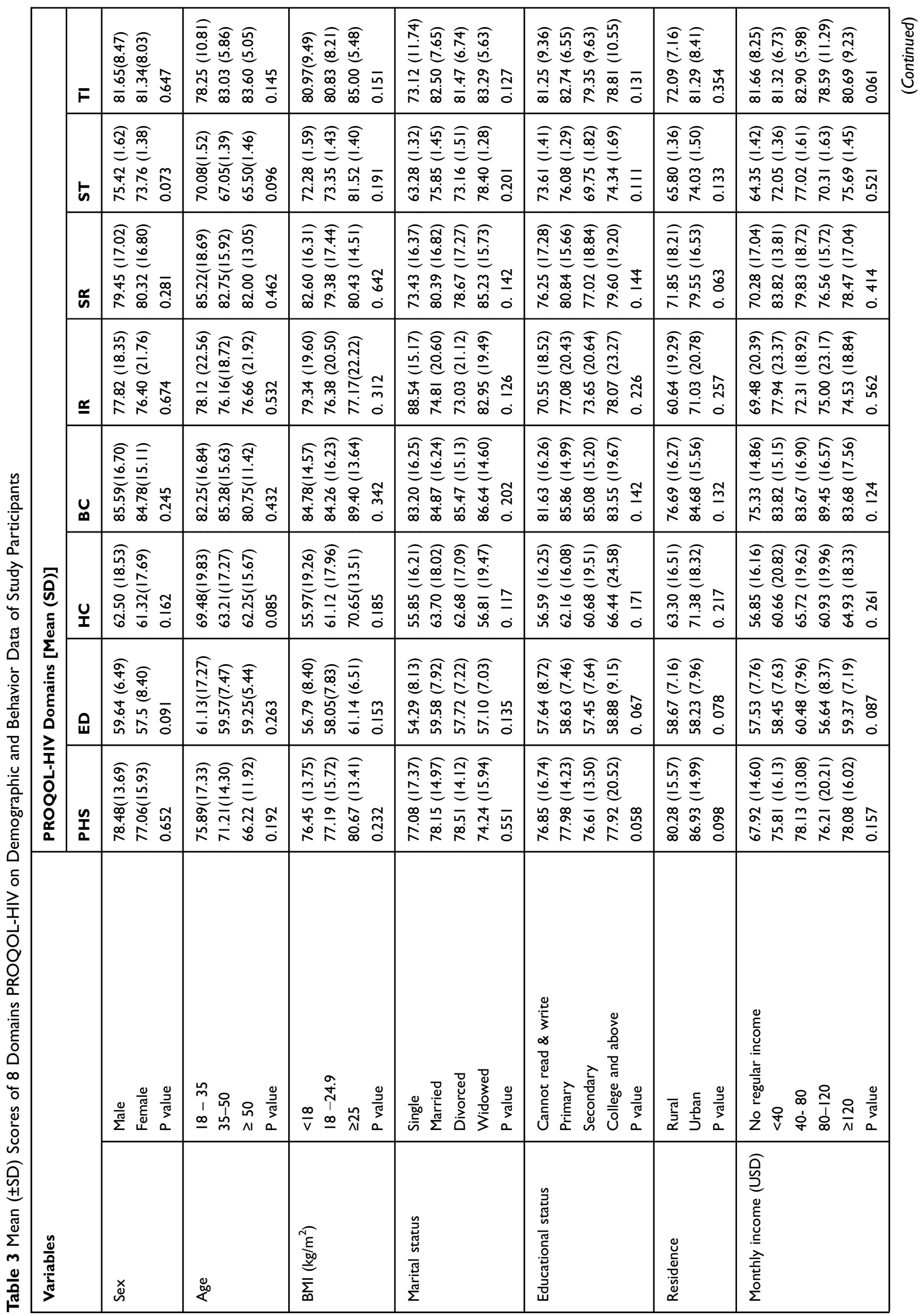




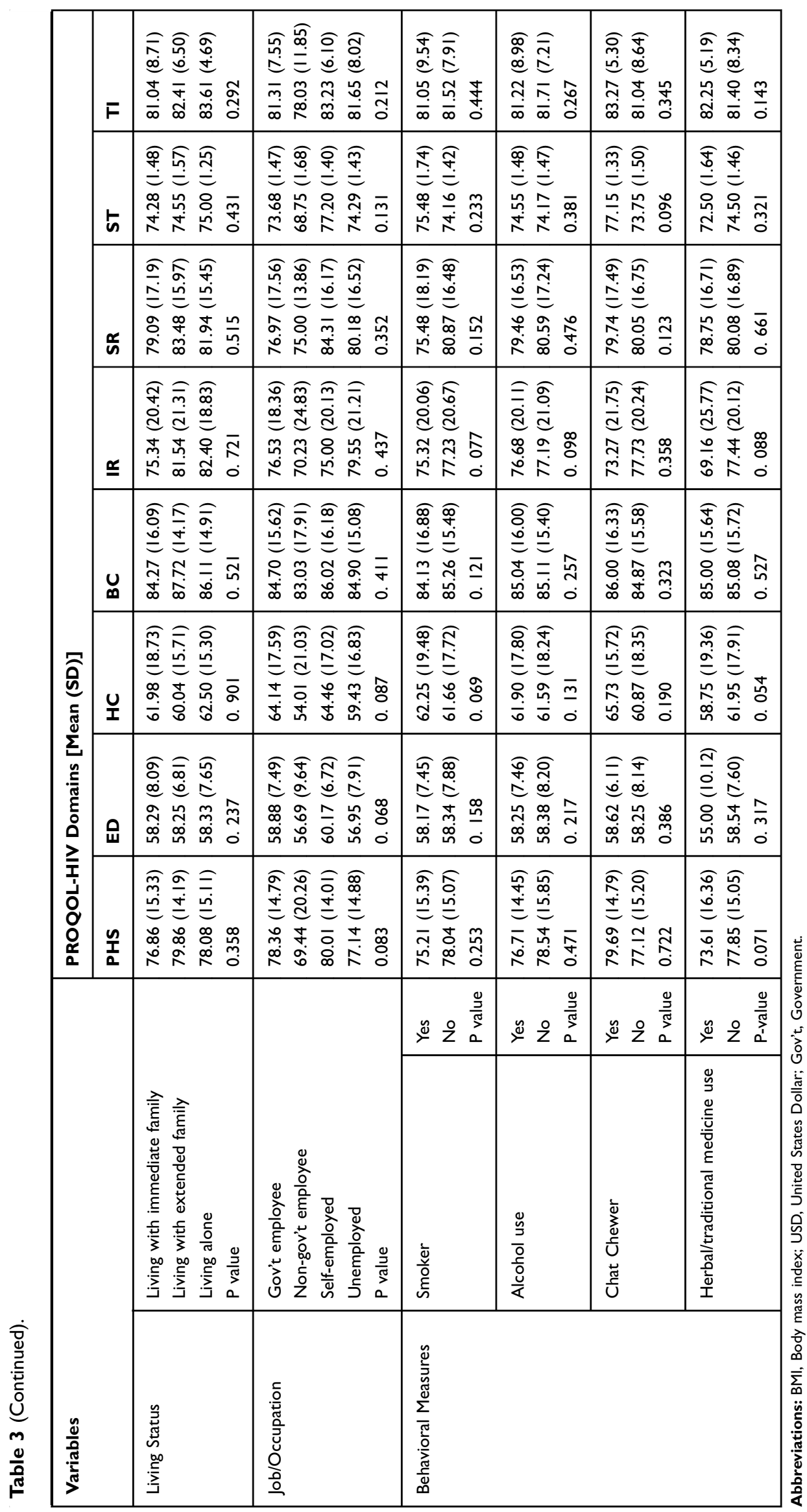




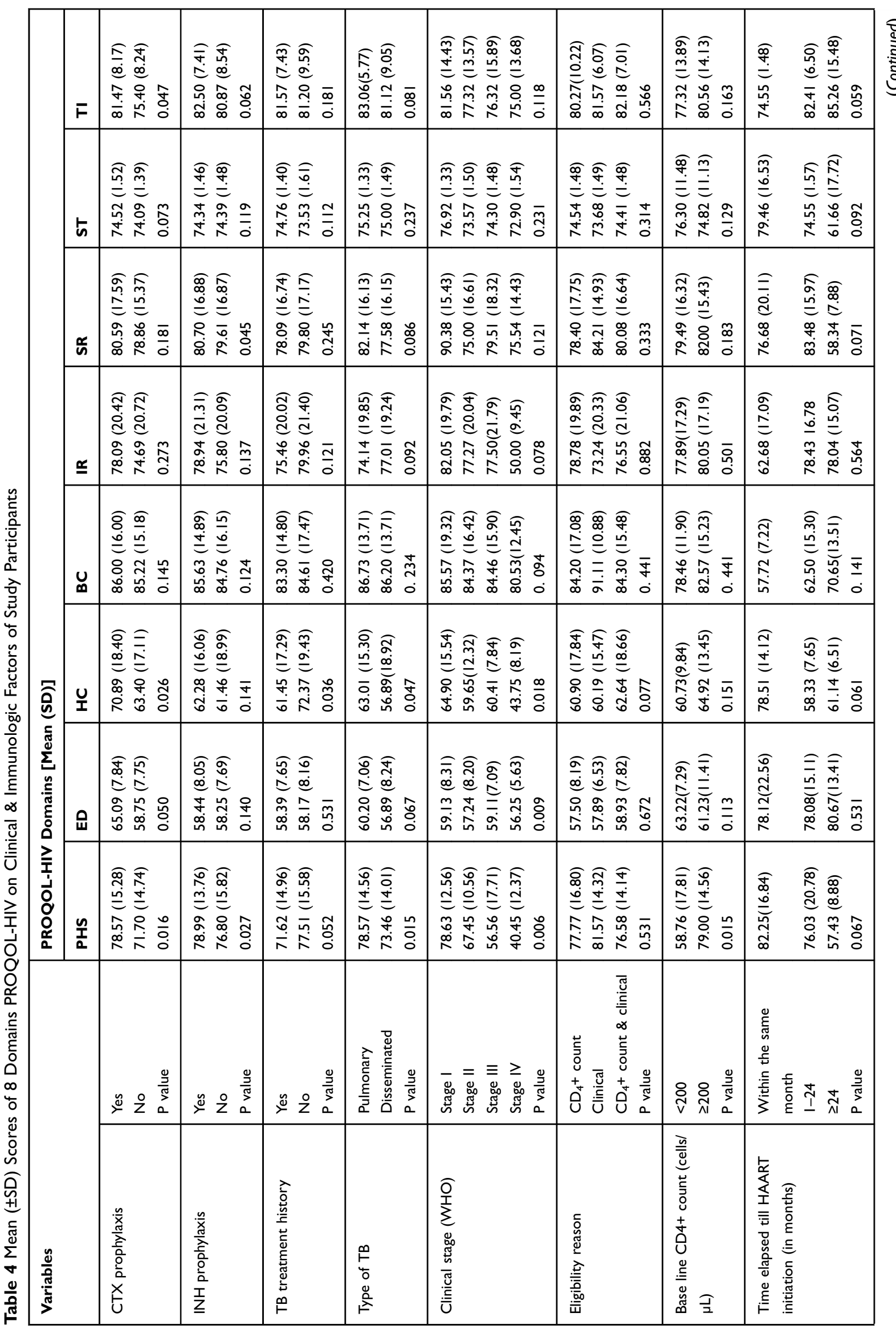




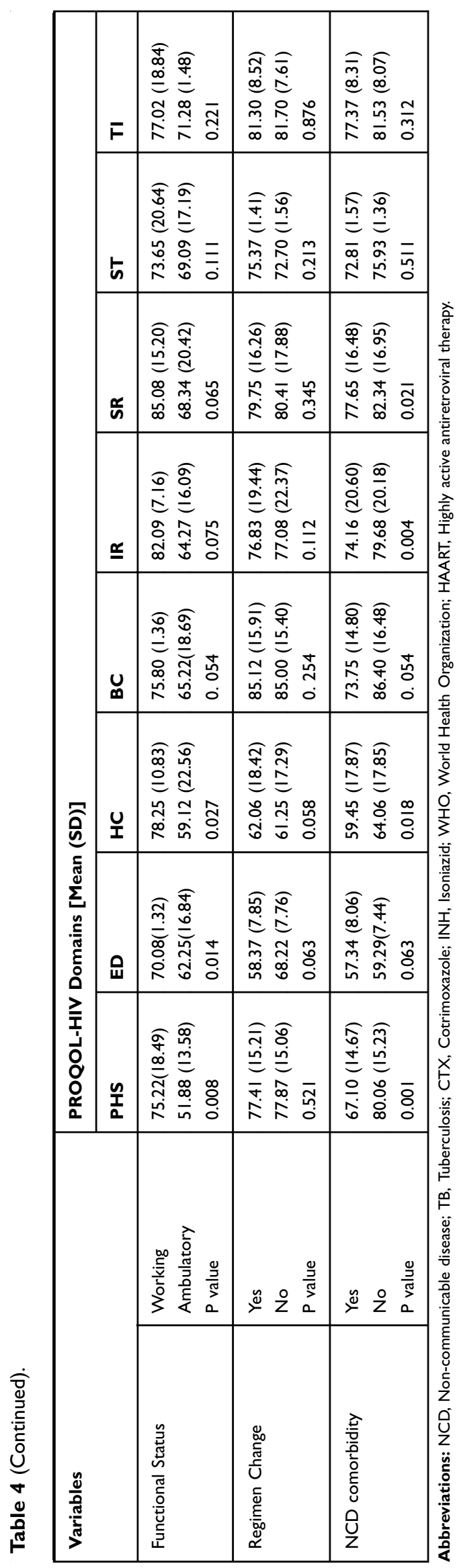

Unemployment negatively influenced all HRQoL domains; largely physical, emotional and social health status. Different studies showed as if employment had a positive indicator for good physical health. ${ }^{25,28-30}$ Since getting a job constitutes a big part of the daily life of people; it can provide structure, a social support network, role identity and meaning. ${ }^{31}$ As well our analysis showed that patients with education reported better quality of life, possibly due to better knowledge about their treatment and disease. This result is similar to another study among HIV/AIDS patients. ${ }^{18}$

Different cross-sectional studies ${ }^{11,20}$ and a longitudinal study $^{22}$ showed a negative association of comorbidity burden on HRQoL, especially on physical health. Likewise, our current findings showed similar results. On the univariate analysis of linear regression, co-existence of NCDs showed negative association across all domains of quality of life measures, especially on physical health symptoms and concerns, social health and intimate relationships, there was a statistically significant association. So, concluding that physical functioning was most affected by the addition of other chronic health problems. Social functioning, mental health functioning, social relationships were also strongly associated with chronic disease burden, which is consistent with other studies. ${ }^{11,32,33}$ Besides this, NCD increased emotional distress, including worrying worseness of HIV infection in the near future as well as had a negative impact on HAART medication experience. These effects may be attributed to the noncommunicable disease itself and/or its medications.

All patients had a relatively better mean score (quality of life) on treatment-related impact (TRT) domain as compared to other domains. Despite their statistical insignificance, some of the patient's baseline information showed a positive association with treatment-related issues. This could be due to the continuous improvements in ART leading to fewer side-effects and possibilities of combination preparations. ${ }^{34,35}$ Some of the variables like living with family (immediate or extended), being on second-line HAART medications $(\mathrm{p}<0.05)$ and non-adherence $(p<0.05)$ showed a significant negative influence on TRT. On PROQOL-HIV instrument, questions were dealing with the size of pills, the number of pills, and frequency of administration as well as taking ARTs in presence of family/friends, which could negatively influence healthrelated quality of life.

Besides this, patients who were initiated on second-line HAART may feel like changing his/her HIV medicine near future, which will have a negative impact on the quality of life. 


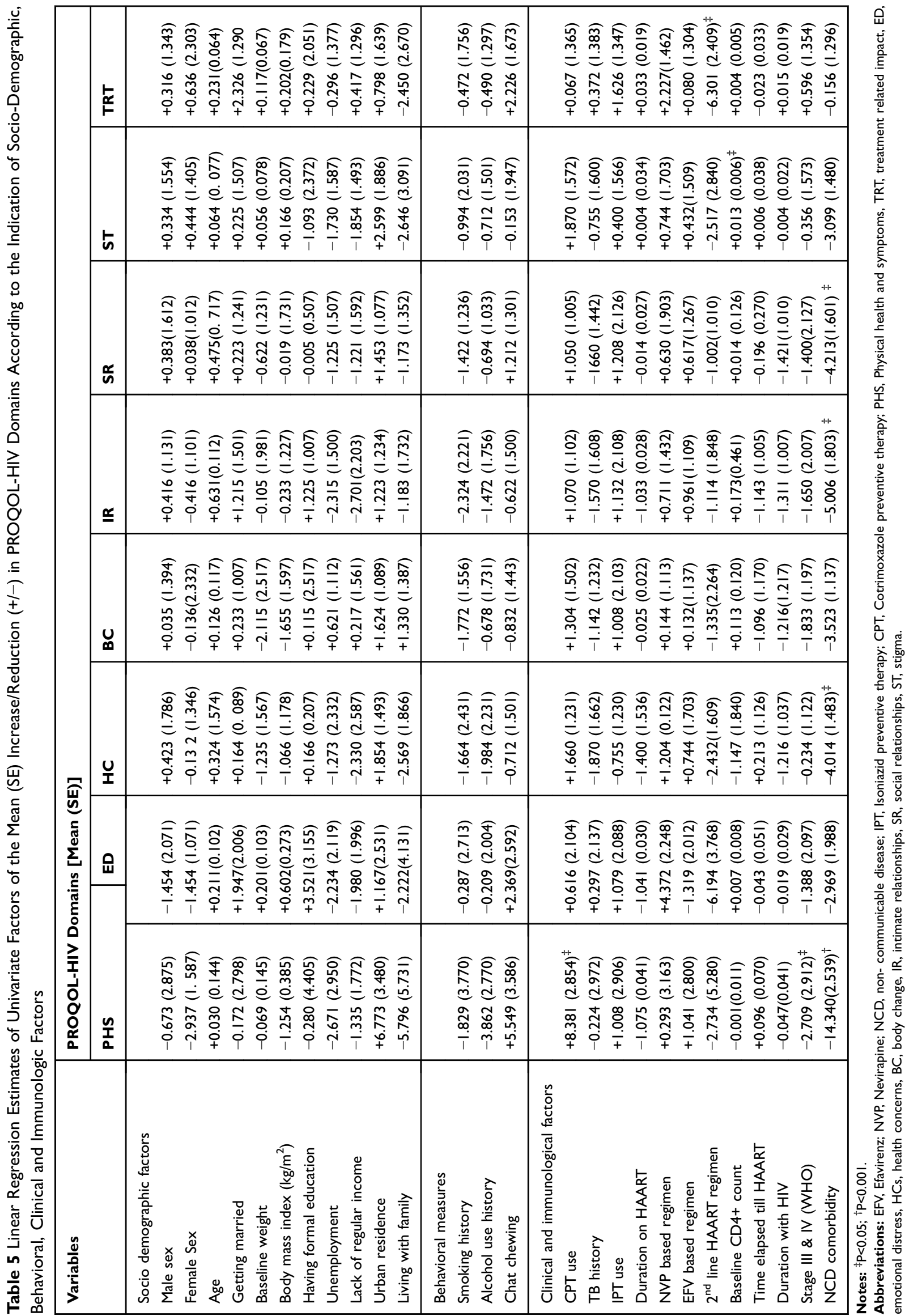


This study also showed prophylactic medications use (i.e. CPT and IPT) had a positive association on the HRQoL of life in all domains, suggesting the importance of these interventions on the improvement of the quality of life. Especially, CPT use had a significant positive association on the physical health and symptoms, which may be related to its effect in the prevention of disabling opportunistic infection(s). Concerning behavioral measures, there was a negative relationship between alcohol intake and smoking and health-related quality of life, which is also reported by recent studies. ${ }^{36,37}$ This may be explained by accelerating in physical function declining, and increased levels of clinical illness and physical and cognitive impairment as well as sleep disturbances.

\section{Limitations of the Study}

This study has limitations. The study sample size was relatively small, and participants were recruited from one tertiary care hospital. Therefore, the generalization of the findings should be cautious and as well as further study is needed to generalize the result and factors affecting the quality of life domains. And, the PROQOL-HIV quality of life scale is not validated for Ethiopia. The strength of this study is, it uses a more contemporaneous scale to measure HRQoL, which has been validated and presents moderate to high correlation to other common scales used in the field.

\section{Conclusions}

In conclusion, our study revealed that HRQoL among PLHIV were negatively influenced by several socioeconomic, behavioral, clinical and immunological factors. Unemployment/lack of regular income, smoking and alcohol intake, tuberculosis infection, second-line HAART medication, non-adherence, and non-communicable disease comorbidity had a negative influence on health-related quality of life.

The burden of chronic NCDs among PLHIV on HRQoL showed a statistically significant negative influence on all dimensions of quality of life measures. Therefore, with HRQoL emerging as a key issue for HIV-infected patients, its routine assessment at each clinic visit would be very crucial. Further research is needed to examine the HRQoL of HIV-infected people, by using this current PROQOLHIV scale, as ours is the first report used this quality of life measuring scale in Ethiopia.

\section{Abbreviations}

HRQoL, Health-related quality of life; JUMC, Jimma University medical center; HIV, Human immune deficiency virus; PROQOL-HIV, Patient-reported quality of life-HIV; PLHIV, People living with human immune deficiency virus; NCD, Non-communicable disease; HAART, highly active antiretroviral therapy; CPT, Cotrimoxazole preventive therapy; IPT, Isoniazid preventive therapy; PHS, Physical health and symptoms; ED, emotional distress; HC, health concerns; $\mathrm{BC}$, body change; IR, intimate relationships; SR, social relationships; ST, stigma; TI, treatment impact; MOS-HIV, Medical Outcomes Survey HIV Health Survey; FAHI, Functional Assessment of HIV Infection; HOPES, HIV Overview of Problems-Evaluation System; HAT-QOL, HIV/AIDS Targeted QOL; AIDSHAQ, AIDS Health Assessment Questionnaire; MQoLHIV, Multidimensional QOL Questionnaire for HIV/ AIDS.

\section{Ethics Approval and Consent to Participate}

Ethical clearance and approval was obtained from the institutional review board (IRB) of Jimma University. Before the start of the survey, informed consent was requested and received from the patient. This study was conducted in accordance with the Declaration of Helsinki.

\section{Data Sharing Statement}

The data sets generated during and/or analyzed during the current study are available from the corresponding authors on reasonable request.

\section{Acknowledgments}

This research study is dedicated to our citizens lost their lives on Irreechaa festival, the Oromo's thanksgiving holiday, on Sunday, 02-October-2016 G.C., at Hora Arsadi, Bishoftu, Oromia, Ethiopia. We would like to acknowledge study participants for their time and dedication to this study and the staff working at TB-HIV follow-up clinic in Jimma University medical center, Ethiopia, for their support during the study. Our deepest heartfelt gratitude also goes to Jimma University for providing grant funds for this research. We have also special thanks to Dr. Martin Duracinsky, for his collaboration in getting the health-related quality of life measuring scale questionnaire. 


\section{Author Contributions}

All authors contributed to data analysis, drafting and revising the article, gave final approval of the version to be published, and agree to be accountable for all aspects of the work.

\section{Funding}

This study was sponsored by Jimma University, Ethiopia.

\section{Disclosure}

The authors have no competing interests to declare. The funder had no role in the study design, data collection, and analysis, decision to publish, or preparation of the manuscript.

\section{References}

1. Sabin CA. The changing clinical epidemiology of AIDS in the highly active antiretroviral therapy era. AIDS. 2002;16:S61-S8. doi:10.1097/ 00002030-200216004-00009

2. Wu AW. Quality of life assessment comes of age in the era of highly active antiretroviral therapy. AIDS. 2000;14(10):1449-1451. doi:10. 1097/00002030-200007070-00019

3. Group W. Development of the World Health Organization WHOQOL-BREF quality of life assessment. Psychol Med. 1998;28 (3):551-558. doi:10.1017/S0033291798006667

4. Sartorius N. The meanings of health and its promotion. Croat Med J. 2006;47(4):662.

5. Bangsberg DR, Hecht FM, Charlebois ED, et al. Adherence to protease inhibitors, HIV-1 viral load, and development of drug resistance in an indigent population. AIDS. 2000;14(4):357-366. doi:10. 1097/00002030-200003100-00008

6. Kaplan RM, Ries AL. Quality of life: concept and definition. COPD. 2007;4(3):263-271. doi:10.1080/15412550701480356

7. Rogers S. Health-Related Quality of Life Among Antiretroviral Therapy (ART) Experienced and ART Naive Adults Attending an Urban HIV Clinic in Kampala. Uganda; 2015.

8. Gakhar H, Kamali A, Holodniy M. Health-related quality of life assessment after antiretroviral therapy: a review of the literature. Drugs. 2013;73(7):651-672. doi:10.1007/s40265-013-0040-4

9. Duracinsky M, Lalanne C, Le Coeur S, et al. Psychometric validation of the PROQOL-HIV questionnaire, a new health-related quality of life instrument-specific to HIV disease. JAIDS $J$ Acq Immun Defic Syndr. 2012;59(5):506-515. doi:10.1097/QAI.0b013e 31824be3f2

10. Deribew A, Deribe K, Reda AA, et al. Change in quality of life: a follow-up study among patients with HIV infection with and without TB in Ethiopia. BMC Public Health. 2013;13(1):408. doi:10.1186/ 1471-2458-13-408

11. Rodriguez-Penney AT, Iudicello JE, Riggs PK, et al. Co-morbidities in persons infected with HIV: increased burden with older age and negative effects on health-related quality of life. AIDS Patient Care STDS. 2013;27(1):5-16. doi:10.1089/apc.2012.0329

12. Briongos Figuero L, Bachiller Luque P, Palacios Martín T, González Sagrado M, Eiros Bouza J. Assessment of factors influencing healthrelated quality of life in HIV-infected patients. HIV Med. 2011;12 (1):22-30. doi:10.1111/hiv.2010.12.issue-1

13. Protopopescu C, Marcellin F, Spire B, et al. Health-related quality of life in HIV-1-infected patients on HAART: a five-years longitudinal analysis accounting for dropout in the APROCO-COPILOTE cohort (ANRS CO-8). Qual Life Res. 2007;16(4):577. doi:10.1007/s11136006-9151-7
14. Rao D, Hahn EA, Cella D, Hernandez L. The health related quality of life outcomes of English and Spanish speaking persons living with HIV/AIDS from the continental United States and Puerto Rico. AIDS Patient Care STDS. 2007;21(5):339-346. doi:10.1089/apc.2006.0124

15. Mrus JM, Williams PL, Tsevat J, Cohn SE, Wu AW. Gender differences in health-related quality of life in patients with HIV/AIDS. Qual Life Res. 2005;14(2):479-491. doi:10.1007/s11136-004-4693-z

16. Cederfjäll C, Langius-Eklöf A, Lidman K, Wredling R. Gender differences in perceived health-related quality of life among patients with HIV infection. AIDS Patient Care STDS. 2001;15(1):31-39. doi:10.1089/108729101460083

17. Perez IR, Bano JR, Ruz ML, et al. Health-related quality of life of patients with HIV: impact of sociodemographic, clinical and psychosocial factors. Qual Life Res. 2005;14(5):1301-1310. doi:10.1007/ s11136-004-4715-x

18. Liu C, Johnson L, Ostrow D, Silvestre A, Visscher B, Jacobson LP. Predictors for lower quality of life in the HAART era among HIV-infected men. JAIDS J Acquir Immun Defic Syndr. 2006;42 (4):470-477. doi:10.1097/01.qai.0000225730.79610.61

19. Kowal J, Overduin LY, Balfour L, Tasca GA, Corace K, Cameron DW. The role of psychological and behavioral variables in quality of life and the experience of bodily pain among persons living with HIV. J Pain Symptom Manage. 2008;36(3):247-258. doi:10.1016/j.jpainsymman.2007.10.012

20. Préau M, Marcellin F, Carrieri MP, et al. Health-Related Quality of Life in French People Living with HIV in 2003: Results from the National ANRS-EN12-VESPA Study. LWW; 2007.

21. Murri R, Fantoni M, Del Borgo C, et al. Determinants of health-related quality of life in HIV-infected patients. AIDS Care. 2003;15(4):581-590. doi:10.1080/0954012031000134818

22. Gibson K, Rueda S, Rourke SB, et al. Mastery and coping moderate the negative effect of acute and chronic stressors on mental health-related quality of life in HIV. AIDS Patient Care STDS. 2011;25(6):371-381. doi:10.1089/apc.2010.0165

23. Douaihy A, Singh N. Factors affecting the quality of life in patients with HIV infection. AIDS Read. 2001;11(9):450-1, 75.

24. Eller LS. Quality of life in persons living with HIV. Clin Nurs Res. 2001;10(4):401-423. doi:10.1177/C10N4R6

25. Hays RD, Cunningham WE, Sherbourne CD, et al. Health-related quality of life in patients with human immunodeficiency virus infection in the United States: results from the HIV cost and services utilization study. Am J Med. 2000;108(9):714-722. doi:10.1016/ S0002-9343(00)00387-9

26. Katz M, Douglas J Jr, Bolan G, et al. Depression and use of mental health services among HIV-infected men. AIDS Care. 1996;8 (4):433-442. doi:10.1080/09540129650125623

27. Ghisvand H, Higgs P, Noroozi M, et al. Social and demographical determinants of quality of life in people who live with HIV/AIDS infection: evidence from a meta-analysis. Biodemography Soc Biol. 2019;1-16.

28. Fleming CA, Christiansen D, Nunes D, et al. Health-related quality of life of patients with HIV disease: impact of hepatitis C coinfection. Clin Infect Dis. 2004;38(4):572-578. doi:10.1086/cid.2004.38.issue-4

29. Rueda S, Raboud J, Mustard C, Bayoumi A, Lavis JN, Rourke SB. Employment status is associated with both physical and mental health quality of life in people living with HIV. AIDS Care. 2011;23 (4):435-443. doi:10.1080/09540121.2010.507952

30. Blalock AC, Mcdaniel JS, Farber EW. Effect of employment on quality of life and psychological functioning in patients with HIV/AIDS. Psychosomatics. 2002;43(5):400-404. doi:10.1176/appi.psy.43.5.400

31. Hoffman MA. HIV disease and work: effect on the individual, workplace, and interpersonal contexts. J Vocat Behav. 1997;51(2):163-201. doi:10.1006/jvbe.1997.1613

32. Imam M, Karim M, Ferdous C, Akhter S. Health related quality of life among the people living with HIV. Bangladesh Med Res Counc Bull. 2011;37(1):1-6. doi:10.3329/bmrcb.v37i1.7791 
33. Ghiasvand H, Waye KM, Noroozi M, Harouni GG, Armoon B, Bayani A. Clinical determinants associated with quality of life for people who live with HIV/AIDS: a meta-analysis. BMC Health Serv Res. 2019;19(1):768. doi:10.1186/s12913-019-4659-z

34. Esté JA, Cihlar T. Current status and challenges of antiretroviral research and therapy. Antiviral Res. 2010;85(1):25-33. doi:10.1016/ j.antiviral.2009.10.007

35. Airoldi M, Zaccarelli M, Bisi L, et al. One-pill once-a-day HAART: a simplification strategy that improves adherence and quality of life of HIV-infected subjects. Patient Prefer Adherence. 2010;4:115-125. doi:10.2147/ppa.s10330
36. Shuter J, Bernstein SL, Moadel AB. Cigarette smoking behaviors and beliefs in persons living with HIV/AIDS. Am $J$ Health Behav. 2012;36(1):75-85. doi:10.5993/AJHB.36.1.8

37. Korthuis PT, Zephyrin LC, Fleishman JA, et al. Health-related quality of life in HIV-infected patients: the role of substance use. AIDS Patient Care STDS. 2008;22(11):859-867. doi:10.1089/apc.2008.0005

\section{Publish your work in this journal}

Patient Related Outcome Measures is an international, peer-reviewed, open access journal focusing on treatment outcomes specifically relevant to patients. All aspects of patient care are addressed within the journal and practitioners from all disciplines are invited to submit their work as well as healthcare researchers and patient support groups.

Submit your manuscript here: http://www.dovepress.com/patient-related-outcome-measures-journal
The manuscript management system is completely online and includes a very quick and fair peer-review system. Visit http://www. dovepress.com/testimonials.php to read real quotes from published authors. 